\title{
Practicalities
}

\author{
(Vol. I. No. 9.)
}

\section{THE TREATMENT OF SOME OF THE CARDIO-VASCULAR DISEASES. Part III}

\author{
By F. CROXON DELLER, M.D., M.R.C.P.
}

Sinus arrhythmia, once recognised, requires no further treatment.

Premature or extra-systoles can often be controlled by the giving of a sedative such as sodium bromide, gr. Io t.d.s. and/or phenobarbitone, gr. $\frac{1}{2}$ nocte et mane. If, however, premature systoles are causing much discomfort to the patient, small doses of quinidine, say 6 or 9 grains daily, may be tried. Potassium chloride gr. 10-25 t.d.s. may be used in some cases with success. But in every case, a search should be made for the exciting cause. If no physical cause can be found, a psychological basis is often present.

In paroxysmal tachycardia the patient may have found some method of controlling the attack. Otherwise pressure over the carotid sinuses with both thumbs, the drinking of a glass of ice-cold water or other forms of vagal stimulation may terminate the attack. If such measures fail drug therapy must be used, especially in the severe case. Carbachol is a most useful drug which is dispensed in tablets containing $2 \mathrm{mgms}$., to be given by mouth in doses of $\frac{1}{2}-2$ tablets, one to three times a day. In the more severe case, subcutaneous or intra-muscular injection of the drug may be necessary. For this purpose carbachol solution is put up in I c.c. ampoules, each containing $2.0 \mathrm{mgm}$. To produce a very rapid effect, the ampoule may be diluted with 9 c.c. of a $20 \%$ glucose solution and 2.5 c.c. of this composite solution given intravenously. Occasionally the injection causes marked circulatory collapse and to counteract this, it has been suggested that 2 or 3 c.c. of cardiazol should be injected intramuscularly prior to the administration of intravenous carbachol. Should carbachol, because of its marked parasympathetic effect, cause cardiac arrest, the immediate intravenous injection of $1 / 100 \mathrm{gr}$. atropine sulphate will produce a restoration of sinus rhythm. Less dramatic yet severe effects may be abolished by the subcutaneous injection of $\frac{1}{50} \mathrm{gr}$. atropine sulphate. If, however, carbachol is not available then quinidine can be used. It may be administered in acute cases in 5 grain doses repeated again in two hours if the requisite effect has not been produced.

If a patient had had several attacks of paroxysmal tachycardia the taking of a carbachol tablet at the onset of any known premonitory symptoms may often avert the attack, or quinidine gr. 3 t.d.s. can be given regularly to try to control the arrhythmia.

Lastly, if the above measures fail prostigmin $0.25-0.5 \mathrm{mgm}$. can be given hypodermically and is often very effective. It has the advantage of having less dramatic and harmful sideactions than carbachol. Potassium chloride in doses of 10-25 gr. three times a day may be used with some benefit occasionally.

The treatment of auricular fibrillation and of auricular flutter has already been discussed when considering the pharmacological and therapeutic action of digitalis and quinidine.

In the severe degrees of heart block little can be done for the arrhythmia and treatment must be directed towards the patient himself, impressing on him the necessity for general care. In the lesser grades of heart block, tab. ephedrine gr. $\frac{1}{2}$ t.d.s. is often useful by decreasing the degree of block present. Barium chloride gr. $\frac{1}{2}$ to $\mathrm{I}$ t.d.s. is also recommended for the relief of the lesser degree of heart block.

Turning to the treatment of hypertension we find it is as difficult as it is complex in its aetiology. In each case it is as well to review the possible causes (see Clinical Study, part III, Nov. I942) and to treat these accordingly. Of the simple measures which are often of some use in practice are the giving of tab. phenobarbitone gr. $\frac{1}{2}$ b.d., a mixture containing acid hydrobrom. dil.m 60 coupled with inf.gentian or inf.quassia, or a mixture containing sodium indide gr. 3-5 t.d.s.

It is well to note here that the sodium salt should be used, and not the potassium salt, although the latter holds a time-honoured position. Each of these suggested receipts may be given over a long period of time. The giving of trinitrin t.d.s. is valueless.

Much has been talked of diet in the treatment of hypertension; in the past, the eating of much red meat has been discouraged, although the efficacy of such a restriction is open to considerable doubt. If the patient is obese, simple dietetic measures directed to the reduction in 
the amount of surplus adipose tissue is an obvious line of treatment, which not only may help the patient's subjective feeling but which does show the patient that an interest is being taken in his case. Over-eating, over-indulgence in alcohol, the ingestion of very spicy and other indigestible foods must be avoided; otherwise a normal plain mixed diet may be allowed, with perhaps a slight preponderance of the vegetable foods. Whisky, well diluted with plain water, and drunk with meals is probably the best of the alcoholic beverages, if the patient insists upon some form of "stimulation." It has the added advantage that it helps to allay that restless feeling from which so many of these patients suffer. Moderation in all things, including smoking, must be enjoined.

Attention must be directed towards any obvious focal sepsis, but a balanced outlook must always be maintained in such a controversial matter as this. Multiple radiographs and investigations tend to do more harm to the patient psychologically than they do therapeutically.

In the hypertension so common in women at the menopause, the administration of tab. stilboestrol $0.5 \mathrm{mgm}$. once or twice daily will often help considerably, not only subjectively but also by reducing the blood pressure slightly in many cases.

Perhaps at some later date, further advances in endocrinology or the use of "renin" may help us further towards more successful therapeutic measures than are now at our disposal.

Lastly mention must be made of the necessity for using discrimination and care in our attitude towards the hypertensive patient. His life must obviously be regulated by the state of his heart, kidney and cerebrum, but needless and irksome restrictions must not be applied too early in the disease process. Rest in bed, coupled with sedatives, is probably the best therapeutic card which.we hold, especially when the patient has an exacerbation of symptoms directly referable to the disease.

Practicalities Vol. II. dealing with diseases of the respiratory system, will begin in the July issue.

\section{BOOK REVIEWS SYNOPSIS OF BLOOD DISEASES}

By A. Piney, M.D., M.R.C.P. Pp. I20. William Heinemann, London. 1942. Price ros. 6d.

In preparing a new synopsis of blood diseases, Dr. Piney sets out "to write a book that will give as much information as the average physician and general practitioner will read and which will also serve the purpose of senior students," illustrated in what the author describes as "a more impressionistic method of drawing and painting." The style throughout, presumably for the sake of brevity, might be described as impressionistic. In the short space of 120 pages, an account is given of all blood diseases and of abnormal blood pictures associated with other conditions, such as infectious and certain tropical diseases. There is also a glossary, an index and charts showing the characteristics of different cell types. Unfortunately, the author seems unacquainted with much of the extremely important recent work on pigment metabolism and haemolytic conditions. For instance, the presence of urobilin in the urine in acholuric jaundice is most unusual except in the presence of liver damage, but it is quoted as a constant finding. No mention is made of the value of vitamin $K$ in haemorrhagic disease of the new born, in fact, vitamin $K$ does not appear in the index. The demonstration of specific lysins in patients with nocturnal haemoglobinurea both by workers in the States and in this country is ignored.

A synopsis to be of value should be both up to date and correct in its information. Dr. Piney has wasted an excellent opportunity.

\section{TROPICAL AND SUB-TROPICAL DISEASES}

By Lieut.-Col. C. H. Barber, D.S.O., M.A., D.M., M.R.C.S., L.R.C.P. Oxford University Press, London, 1942. Price 5s.

If the experience of the last war is a reliable guide, young medical officers proceeding on service to the tropics often find themselves at a peculiar disadvantage when they are called upon to treat patients under conditions that are entirely strange and with facilities for diagnosis much inferior to those to which they have been accustomed at home. Bewildered often by an almost complete absence of physical signs, they are tempted to take the easy course of diagnosing every fever as malaria, and every case of diarrhoea as "gyppy tummy." What they require is a small text-book of tropical medicine that will give them a simple straightforward account of the common diseases they are likely to meet with and assist them in their diagnosis. The Oxford War Manual on "Tropical and Sub-tropical Diseases" by Lieut.-Col. C. H. Barber should supply this want. In spite of its small size, the author has succeeded by means of a summarised style, aided by line drawings and a number of differential tables, in packing into it much useful information. The order of the contents is at times illogical, typhoid fever, for example coming between bilharziasis and smallpox; and much of the bacteriology is out of date or misleading. These faults may perhaps be remedied in a second edition. In the meantime we wish the present volume every success. 